\title{
Diagnostic Work-up and Follow-up in Children with Tall Stature: A Simplified Algorithm for Clinical Practice
}

\author{
Susanne E. Stalman 1,2* Anke Pons ${ }^{1 *}$, Jan M. Wit3, Gerdine A. Kamp1, Frans B. Plötz1 \\ 1 Tergooi Hospitals, Department of Pediatrics, Blaricum, The Netherlands \\ 2Academic Medical Center, Department of Pediatrics, Amsterdam, The Netherlands \\ 3 Leiden University Medical Center, Department of Pediatrics, Leiden, The Netherlands
}

\section{WHAT IS ALREADY KNOWN ON THIS TOPIC?}

Various expert-based flow charts about diagnostic work-up for tall stature have been proposed, focusing on identifying pathological causes for tall stature. No exact data are available on the incidence of pathological causes of tall stature, but most clinicians consider these rare.

\section{WHAT THIS STUDY ADDS?}

Our study shows an incidence of pathological causes of perceived tall stature of $1.5 \%$ and that adult height reduction is seldom indicated. Of the non-pathological cases, most are familial (compared with sex-corrected midparental height as well as with height of the tallest parent), but constitutional advancement of growth and unexplained non-familial tall stature are also observed. We suggest a simplified diagnostic algorithm and recommendations for follow-up.

\section{ABSTRACT}

Objective: No evidence-based guideline has been published about optimal referral criteria and diagnostic work-up for tall stature in children. The aim of our study was to describe auxological and clinical characteristics of a cohort of children referred for tall stature, to identify potential candidates for adult height reduction, and to use these observations for developing a simple algorithm for diagnostic work-up and follow-up in clinical practice.

Methods: Data regarding family and medical history, auxological measurements, bone age development, physical examination, additional diagnostic work-up, and final diagnosis were collected from all children referred for tall stature, irrespective of their actual height standard deviation score (HSDS). Predicted adult height (PAH) was calculated in children above 10 years. Characteristics of patients with an indication for adult height reduction were determined.

Results: Hundred thirty-two children (43 boys) with a mean \pm SD age of $10.9 \pm 3.2$ (range 0.5-16.9) years were included in the study. Fifty percent of the referred children had an HSDS $\leq 2.0$ ( $n=66)$. Two pathological cases (1.5\%) were found (HSDS 2.3 and 0.9 ). Tall children without pathology were diagnosed as idiopathic tall, further classified as familial tall stature $(80 \%)$, constitutional advancement of growth (5\%), or unexplained non-familial tall stature (15\%). Of the 74 children in whom PAH was calculated, epiphysiodesis was considered in six $(8 \%)$ and performed in four (5\%) patients.

Conclusion: The incidence of pathology was very low in children referred for tall stature, and few children were potential candidates for adult height reduction. We propose a simple diagnostic algorithm for clinical practice.

Key words: Children, growth monitoring, height, target height, tall stature, overgrowth, height reduction

Conflict of interest: None declared

Received: 20.07 .2015

Accepted: 08.09 .2015

Address for Correspondence

Susanne E. Stalman MD, Tergooi Hospitals, Department of Pediatrics, Blaricum, The Netherlands Phone: +44 7719955593 E-mail: s.e.stalman@amc.uva.nl @ Journal of Clinical Research in Pediatric Endocrinology, Published by Galenos Publishing. 


\section{Introduction}

Tall stature is defined as a height of more than 2.0 standard deviations (SD) above the corresponding mean height for age and sex as observed in the population $(1,2)$. Although there are as many children with tall stature as children with short stature, tall stature is a less common reason for referral from primary health care to specialist care than short stature (2).

There are two main reasons to refer children with tall stature. First, like in short stature, it is important to distinguish between normal variation and pathology (3). There is some confusion about the nomenclature of non-pathological causes of tall stature. In the European Society for Paediatric Endocrinology (ESPE) Classification of Paediatric Endocrine Diagnoses (3), this group was denominated as idiopathic tall stature (ITS) and further subdivided into genetic (familial) tall stature (or constitutional tall stature) and non-familial tall stature (NFTS). Later, several authors coined the term "constitutional advancement of growth (CAG)" $(1,3,4)$ for tall children with a height beyond the target height $(\mathrm{TH})$ range but with coincident bone age (BA) advance, who therefore would be expected to end up with a normal adult height. The second reason for referral of tall children is to predict adult height and thus to identify potential candidates for adult height reduction (5). Recommendations regarding follow-up of tall children are lacking, in particular with respect to indications for interventions to reduce adult height. We have learned from clinical experience that some children with a normal height can reach very tall adult stature if bone maturation and/or puberty are extremely delayed. In addition, only few data have been published about the characteristics of patients who eventually underwent adult height reduction by epiphysiodesis $(5,6)$.

So far, no evidence-based (inter) national guideline has been published about optimal referral criteria, diagnostic work-up, and follow-up for tall stature. Various expert-based algorithms have been proposed to identify pathological causes although in the majority, no pathology can be found $(1,4,7)$. Here, our first aim was to describe auxological and clinical characteristics of a cohort of children referred for tall stature to a general pediatric clinic. Our second aim was to identify potential candidates for adult height reduction. Based on these observations and published literature, we propose a simple algorithm for diagnostic work-up and follow-up of children with tall stature which, we hope, will be prospectively validated in the future.

\section{Methods}

\section{Study Population}

In this study, we included all children referred for tall stature, irrespective of their actual height standard deviation score (HSDS), to the general (non-academic) pediatric growth clinic of Tergooi Hospitals in the Netherlands between January
2010 and March 2014. Exclusion criteria were ethnicity other than Dutch (defined as at least one parent with non-western European ethnicity) and missing medical records.

\section{Data Collection}

All patients underwent a four-step diagnostic program. First, the parents completed a questionnaire regarding perinatal and medical history (with special attention to psychomotor/ mental development and behavior), medication use, pubertal signs, growth and family history regarding height, puberty onset and medical history of first-degree relatives. Second, BA was assessed by a single pediatrician (G.K.) according to the method of Greulich and Pyle (8) and BA advance or delay was calculated as BA minus chronological age (CA). Third, height, weight, head circumference, sitting height $(\mathrm{SH})$, arm span, blood pressure, and heart rate were measured. Parental height could be measured in most cases (approximately $95 \%)$, the remaining parental height data were based on reported values. $\mathrm{TH}$ was calculated based on father's height (FH) and mother's height ( $\mathrm{MH}$ ) according to two equations, both without secular trend correction. We used the traditional Tanner formula [(FH+MH)/2+ or -6.5] (9) and conditional TH (cTH) based on the most recent Dutch growth study reported by van Dommelen et al (10) $(44.5+0.376 x \mathrm{FH}+0.411 \times \mathrm{MH}$ for boys and $47.1+0.334 \times \mathrm{FH}+0.364 \times \mathrm{MH}$ for girls). SDS of the following items were calculated based on appropriate reference data: height (HSDS) (11); TH (in cm and SDS) (9) and cTH (in cm and SDS) (10); body mass index (BMI) (12); head circumference (13); sitting height/height ratio $(\mathrm{SH} / \mathrm{H})(14)$; and birth weight, length and head circumference (15). The HSDS distance to THSDS according to Tanner as well as to cTHSDS according to van Dommelen et al (10) was calculated, and we also calculated the difference between the patient's HSDS and the HSDS of the tallest parent. Predicted adult height (PAH) was calculated in children above 10 years according to Bayley and Pinneau (16) and an update of the formula of De Waal et al (17) based on the change of the $\mathrm{TH}$ formula because of the discontinuation of secular trend in the Netherlands (11): $267.02+(0.62 \times$ height $)+(2.75 \times c T H S D S)-(10.49 \times C A)-$ $(12.98 \times B A)+(0.72 \times C A \times B A)$ for boys and 158.42+(0.74xheight) + (1.47xcTHSDS) - (5.90xCA) - (7.70xBA) + (0.41xCAxBA) for girls (Wit and van Dommelen, personal communication). Finally, one pediatrician (G.K.) reviewed the questionnaire, BA, and the auxological measurements and performed a complete physical and neurological examination. The physical examination was focused on detecting body disproportion (defined as $\mathrm{SH} / \mathrm{H}$ ratio >-2.2 SDS) (14) and specific dysmorphic features rated on syndrome-specific checklists. Pubertal development was rated according to Tanner $(18,19)$.

\section{Diagnostic Work-up}

Briefly, diagnostic work-up in order to uncover pathologic causes for tall stature was considered in case of presence of the following features: developmental and/or speech delay, behavioral problems, dysmorphisms, disproportion, a distance 
between HSDS and THSDS >2.0, a recent growth acceleration, pubertal development not appropriate for age, or indications of other hormonal disorders such as growth hormone excess or hyperthyroidism.

\section{Definitions}

Pathological tall stature was subclassified into two categories: children with a dysmorphic syndrome with overgrowth (primary growth disorder) and those with tall stature caused by endocrine diseases (secondary growth disorder) (3). Non-pathological tall stature is considered a normal variant, probably caused by multiple gene variants with a positive effect on linear growth (20) and maturation. Because the precise etiology is unknown, this condition is termed ITS in the ESPE Classification of Paediatric Endocrine Diagnoses (3), and further classified into two subclasses: familial tall stature (FTS) (explained by gene variants associated with linear growth) and NFTS. In our study, we further distinguished in the latter group two conditions: CAG (hypothetically explained by gene variants associated with a fast tempo of growth, "maturation") and others unexplained by genetic factors.

Three ways to distinguish FTS from were used. First, FTS was defined as a HSDS distance to THSDS $<2.0$ based on the Tanner equation and $\mathrm{TH}$ range of $+/-2.0 \mathrm{SD}$ (9). Second, we subclassified the children based on the distance to cTHSDS (10), with a cTH range of +/-1.6 SD (children with a HSDS minus cTHSDS <1.6 were classified as FTS). Third, we reasoned that tall height can appear as a dominantly inherited condition, either monogenic (e.g., in Marfan syndrome), or polygenic (if the child inherits by chance mostly "tall gene variants" from the tallest parent). So, tall children were also denominated as FTS if they were tall $(H S D S>+2.0)$ and their HSDS minus HSDS of the tallest parent was below +1.6. CAG was defined as NFTS with an advanced $B A>2.0$ years (8).

Children with a HSDS $\leq 2.0$ were classified as 'not-tall'. These children were included in the study because the reason for referral was identical to that of children with a HSDS >2.0. Characteristics of not-tall and tall children were compared, including their HSDS, THSDS, HSDS-THSDS, BMI, BA-CA, and $\mathrm{PAH}$ data.

\section{Adult Height Reduction}

Adult height reduction by epiphysiodesis was considered for a PAH of $>205 \mathrm{~cm}(+3.0$ SDS) in boys or $>185 \mathrm{~cm}(+2.3$ SDS) in girls (5) with PAH based on the formula of De Waal et al (17), since this is considered the most accurate for tall stature in the Netherlands. These patients were assessed separately to determine the characteristics of this group. Furthermore, children with a PAH $>205 \mathrm{~cm}$ (boys) or $>185 \mathrm{~cm}$ (girls), regardless of their HSDS at presentation, were assessed to identify patients with a HSDS $\leq 2.0$ at presentation who might still have an indication for adult height reduction and to determine their characteristics.

\section{Analysis}

All data were collected from hospital files and were analysed in Statistical Package for the Social Sciences, version 19. Descriptive statistics were used to quantify the prevalence of pathologic causes for tall stature and the analysis of the different diagnostic group characteristics. Independent t-tests for continuous variables and chi-square tests for categorical variables were used to compare characteristics between boys and girls and between different diagnostic groups. A value of $\mathrm{p}<0.05$ (two-sided) was considered statistically significant.

\section{Ethical Approval}

Approval for the study was obtained by the Scientific Review Committee of Tergooi Hospitals (letter reference kv/15.05).

\section{Results}

\section{Study Population}

During this study period, 139 children were referred for tall stature, of whom seven children were excluded because of missing data $(n=4)$ or non-Dutch ethnicity $(n=3)$. Patient characteristics of the 132 children included for analysis are shown in Table 1.

\section{Diagnostic Work-up}

The adherence to our initial four-step diagnostic work-up protocol was $100 \%$ and additional diagnostic work-up was performed in 19 patients (14.4\%) based on clinical judgement using a local protocol and various flow charts $(1,4,7)$. In 5 children with dysmorphic features, one of whom showed slight body disproportion (long legs), genetic testing revealed no specific diagnosis (Marfan syndrome was excluded). In ten children, the head circumference was >2.0 SDS. Given the low Sotos score on the checklist (21), no diagnostic work-up was indicated. Thirteen children did not meet any of the three definitions for FTS (HSDS-THSDS >2.0, HSDScTHSDS > 1.6, and HSDS-HSDS of tallest parent >1.6). Three of these children had an advanced BA of $>2.0$ years and were classified as CAG. Seven children had an advanced BA of $>1.0$ year (1.2-1.9 SDS). Additional work-up was performed in two out of these seven children to rule out secondary growth disorders, which revealed no abnormalities. In the remaining five, no diagnostic work-up was performed, but during follow-up, no abnormal growth pattern was observed. In two out of three pre-pubertal patients with a recent growth acceleration, additional work-up was performed and revealed no specific diagnosis. In six patients with a pubertal development not appropriate for age, the additional work-up showed precocious puberty in two patients. Diagnostic workup to reveal secondary growth disorders was performed in six children and found negative. 


\section{Diagnoses}

A pathological cause of tall stature was found in the two patients with precocious puberty $(1.5 \%)$. In one patient, the diagnosis was made based on clinical features (recent growth acceleration, HSDS 2.3, an advanced BA development, a reported onset of puberty of 7.5 years, and Tanner pubertal stage B3/P3 at the age of 9.4 years) (22). In the other patient (5.3 years), the diagnosis was based on clinical features (pubertal development, Tanner B2/P1, HSDS 0.9) and a positive gonadotropin-releasing hormone test.

Figure 1 shows histograms of HSDS minus THSDS (a), HSDS minus cTH (b) and the child's HSDS minus HSDS of the tallest parent (c). The mean values are 0.9, 1.2, and 0.4, showing that the child's height is on average closest to the tallest parent's height. The number of idiopathic tall children labelled FTS according to the three definitions (HSDS-THSDS $>2.0$, HSDS-cTH $>1.6$ and HSDS-HSDS of tallest parent $>1.6)$ was 50 (77\%), 21 (32\%), and 46 (71\%), respectively. Fifty-two children complied with at least one of these definitions (80\%) and were labelled FTS. Of the 13 children with NFTS, 3 were labelled CAG. Figure 2 demonstrates the correlation between HSDS distance to THSDS (Tanner) and BA development in the 65 children with non-pathological tall stature, showing a relatively advanced BA development in children who are taller than THSDS (Pearson correlation 0.45, p<0.01).

Exactly fifty percent of the children referred for tall stature had an HSDS $\leq 2.0 \quad(n=66)$, so were classified as not-tall (Table 2). There was no difference in THSDS between both groups, but tall children had a significantly more advanced BA development compared to not-tall. To answer the question why so many not-tall children were indeed referred with "a fear to become too tall", we evaluated their family history regarding parental height and parental pubertal development, showing that in 33 out of 66 (50\%) not-tall children, at least one parent had a HSDS $>2.0$ or had a delayed puberty, compared to 29 out of $66(44 \%)$ tall children $(p=0.49)$.

\section{Adult Height Reduction}

In all 74 children above 10 years of age, $\mathrm{PAH}$ was calculated (Table 1). PAH based on Bayley and Pinneau (16) resulted in five boys with a prediction $>205 \mathrm{~cm}$ and 13 girls with a prediction $>185 \mathrm{~cm}$. Of these patients, two boys and two girls had a HSDS $\leq 2.0$. Both girls had a delay in puberty. Using the De Waal method, we found that none of the boys had a $\mathrm{PAH}>205 \mathrm{~cm}$, while six girls had a $\mathrm{PAH}>185 \mathrm{~cm}$. One of these girls was not tall, but she had pubertal delay. Four patients $(3.0 \%)$ wished to be referred for adult height reduction by epiphysiodesis (Table 3 ). One girl who underwent epiphysiodesis did not meet the criteria for treatment at the first presentation, but did so on return two years later.

\section{Discussion}

In our population referred for tall stature, 50\% had indeed a height $>2.0$ SDS. Two patients were diagnosed with precocious puberty (1.5\%); one of them had a HSDS of 0.9 , but a recent growth acceleration. Of the idiopathic tall children, $80 \%$ were diagnosed as FTS, $5 \%$ as CAG and $15 \%$ remained unexplained. In all children older than 10 years $(n=74)$ PAH was

Table 1. Characteristics of the study population, according to gender

\begin{tabular}{|c|c|c|c|c|}
\hline & Total $n=132$ & Boys $n=43(32.6 \%)$ & Girls $n=89(67.4 \%)$ & Sign \\
\hline Age, years & $10.9 \pm 3.2(0.5-16.9)$ & $10.1 \pm 3.8(1.7-16.9)$ & $11.2 \pm 2.9(0.5-16.6)$ & $\mathrm{p}=0.10$ \\
\hline HSDS & $2.0 \pm 0.7(0.1-3.7)$ & $2.4 \pm 0.7(0.7-3.7)$ & $1.9 \pm 0.7(0.1-3.5)$ & $\mathrm{p}<0.01$ \\
\hline THSDS (Tanner) & $1.1 \pm 0.7(-0.9-2.6)$ & $1.0 \pm 0.6(-0.7-2.4)$ & $1.2 \pm 0.7(-0.9-2.6)$ & $p=0.60$ \\
\hline cTH SDS (van Dommelen) & $0.8 \pm 0.5(-0.7-1.9)$ & $0.8 \pm 0.5(-0.5-1.9)$ & $0.8 \pm 0.5(-0.7-1.8)$ & $\mathrm{p}=0.61$ \\
\hline $\mathrm{SH} / \mathrm{H}$ ratio SDS & $-0.5 \pm 0.7(-2.2-1.1)$ & $-0.4 \pm 0.8(-2.2-1.0)$ & $-0.6 \pm 0.7(-1.9-1.1)$ & $p<0.05$ \\
\hline$B A-C A$, years & $0.4 \pm 1.3(-3.9-4.3)$ & $0.7 \pm 1.3(-2.4-3.5)$ & $0.2 \pm 1.3(-3.9-4.3)$ & $\mathrm{p}=0.02$ \\
\hline BL SDS & $1.6 \pm 1.5(-3.6-4.9)$ & $1.6 \pm 1.9(-3.6-4.9)$ & $1.6 \pm 1.2(-0.5-4.1)$ & $\mathrm{p}=0.98$ \\
\hline BW SDS & $0.7 \pm 1.0(-2.5-3.0)$ & $0.8 \pm 1.1(-2.5-2.8)$ & $0.7 \pm 1.0(-1.8-3.0)$ & $\mathrm{p}=0.95$ \\
\hline GA, weeks & $39.6 \pm 1.9(32.0-42.0)$ & $39.4 \pm 1.8(33.4-42.0)$ & $39.6 \pm 1.9(32.0-42.0)$ & $p=0.52$ \\
\hline BMI SDS & $0.2 \pm 1.1(-2.6-3.0)$ & $0.5 \pm 1.1(-1.5-3.0)$ & $0.1 \pm 1.0(-2.6-2.4)$ & $p=0.05$ \\
\hline $\begin{array}{l}\text { PAH (De Waal) } \\
\text { SDS ( } \geq 10 \text { years) }\end{array}$ & $1.6 \pm 0.6(-0.3-2.7)$ & $1.8 \pm 0.7(-0.3-2.7)$ & $1.5 \pm 0.6(-0.2-2.6)$ & $p=0.11$ \\
\hline $\begin{array}{l}\text { PAH (Bayley and Pinneau) } \\
\text { SDS ( } \geq 10 \text { years) }\end{array}$ & $1.8 \pm 0.9(-0.3-2.7)$ & $2.4 \pm 0.7(0.2-4.0)$ & $1.6 \pm 0.8(-0.3-3.3)$ & $p<0.01$ \\
\hline \multicolumn{5}{|c|}{$\begin{array}{l}\text { Mean } \pm \text { SD (range) } \\
\text { HSDS: height standard deviation score, THSDS: target height standard deviation score (according to Tanner), cTH SDS: conditional target height standard deviation score (according } \\
\text { to van Dommelen), SH/H: sitting height/height ratio, BA-CA: bone age minus chronological age, BL: birth length, BW: birth weight, GA: gestational age, BMI: body mass index, PAH: } \\
\text { predicted adult height *PAH calculated in } 74 \text { patients (18 boys and } 56 \text { girls) }\end{array}$} \\
\hline
\end{tabular}


Stalman SE et al.

Diagnostic Work-up and Follow-up in Tall Children

Table 2. Characteristics of not-tall and tall boys and girls

\begin{tabular}{|c|c|c|c|c|}
\hline & \multicolumn{2}{|l|}{ Boys } & \multicolumn{2}{|l|}{ Girls } \\
\hline & Not-tall $n=14$ & Tall $n=29$ & Not-tall $n=52$ & Tall $n=37$ \\
\hline Age at presentation, years & $11.5 \pm 3.4(5.5-16.7)$ & $9.5 \pm 3.8(1.7-16.9)$ & $11.4 \pm 2.7(5.3-15.6)$ & $10.9 \pm 3.2(0.5-16.6)$ \\
\hline HSDS & $1.6 \pm 0.4(0.7-2.0)^{*}$ & $2.7 \pm 0.4(2.1-3.7)^{*}$ & $1.4 \pm 0.5(0.1-2.0)^{*}$ & $2.6 \pm 0.4(2.1-3.5)^{*}$ \\
\hline THSDS (Tanner) & $1.0 \pm 0.7(-0.7-2.0)$ & $1.0 \pm 0.6(-0.2-2.4)$ & $1.2 \pm 0.7(-0.9-2.6)$ & $1.2 \pm 0.7(-0.3-2.6)$ \\
\hline HSDS-THSDS (Tanner) & $0.6 \pm 0.9(-0.8-2.8)^{*}$ & $1.7 \pm 0.7(0.0-3.2)^{*}$ & $0.2 \pm 0.9(-2.1-2.9)^{*}$ & $1.4 \pm 0.7(0.1-2.6)^{*}$ \\
\hline BMI SDS & $0.4 \pm 0.9(-1.0-2.0)$ & $0.5 \pm 1.1(-1.5-2.7)$ & $0.0 \pm 1.0(-2.6-1.8)$ & $0.2 \pm 1.1(-2.1-2.4)$ \\
\hline BA-CA, years & $0.2 \pm 1.5(-2.4-3.5)^{*}$ & $1.0 \pm 1.1(-1.8-3.5)^{*}$ & $-0.1 \pm 1.1(-2.7-2.5)^{*}$ & $0.7 \pm 1.2(-2.4-4.3)^{*}$ \\
\hline PAH (De Waal) SDS ( $\geq 10$ years) ${ }^{\star *}$ & $1.6 \pm 0.9(-0.3-2.4)$ & $2.0 \pm 0.6(0.8-2.7)$ & $1.2 \pm 0.5(-0.2-2.3)^{*}$ & $2.0 \pm 0.3(1.4-2.6)^{*}$ \\
\hline $\begin{array}{l}\text { PAH (Bayley and Pinneau) } \\
>205 \mathrm{~cm} \text { in boys } \\
>185 \mathrm{~cm} \text { in girls }\end{array}$ & $n=2$ & $n=3$ & $n=2$ & $n=11$ \\
\hline $\begin{array}{l}\text { PAH (De Waal) } \\
>205 \mathrm{~cm} \text { in boys } \\
>185 \mathrm{~cm} \text { in girls }\end{array}$ & $n=0$ & $n=0$ & $n=1$ & $n=5$ \\
\hline $\begin{array}{l}\text { Mean } \pm \text { SD (range) } \\
\text { HSDS: height standard deviation score, THS } \\
\text { PAH: predicted adult height } \\
{ }^{*} \text { p }<0.05 \\
{ }^{*} \text { PAH calculated in } 7 \text { not-tall boys, } 11 \text { tall bo }\end{array}$ & theight standard devi & cording to Tanner), & index, BA-CA: bone & us chronological age, \\
\hline
\end{tabular}

Table 3. Characteristics of 4 patients who underwent epiphysiodesis

\begin{tabular}{|l|l|l|l|l|l|}
\hline Sex & Male & Female & Female & Female \\
\hline Age at presentation, years & 15.8 & 10.5 & 12.5 & 13.0 & 14.9 \\
\hline HSDS & 2.4 & 2.7 & 2.6 & 2.6 & 2.0 \\
\hline THSDS & 1.2 & 2.6 & 2.5 & 2.3 & 0.5 \\
\hline BA-CA, years & -1.83 & 0.74 & -0.28 & -0.53 & -2.68 \\
\hline PAH SDS (cm) (De Waal) & $2.7(203.1)$ & $1.9(182.8)$ & $2.4(185.8)$ & $2.5(186.5)$ & $2.3(185.1)$ \\
\hline PAH SDS (cm) (Bayley and Pinneau) & 4.0 (211.9) & 1.7 (181.1) & $2.3(185.2)$ & $3.0(189.7)$ & 3.3 (191.7) \\
\hline HSDS: height standard deviation score, THSDS: target height standard deviation score (according to Tanner), BA-CA: bone age minus chronological age, PAH: predicted adult height \\
\hline
\end{tabular}

calculated, and in only six (8\%), epiphysiodesis was considered and eventually performed in four (5\%) patients.

Although the incidence of pathology in children referred for tall stature is very low, it remains important to rule out chromosomal, genetic, or endocrine disorders. A careful history, in particular developmental delay and behavioral problems, may be suggestive for chromosomal disorders, whereas specific findings on examination, like dysmorphisms and macrocephaly, may be suggestive for specific genetic syndromes. The most common genetic causes of tall stature are Klinefelter syndrome, Marfan syndrome, Sotos syndrome, and Beckwith-Wiedemann syndrome (BWS) (23), with an incidence of 1.1-1.7 per 1000 (24), 2-3 per 10.000 (25), 1 per 15.000 (26), and 1 per 13.700
(27) individuals, respectively. Precocious puberty is the most common endocrine cause of accelerated growth. Based on these numbers, it is not unexpected that no primary growth disorders and only two secondary growth disorders have been diagnosed in our population.

To determine whether tall stature is familial or not, the usual approach has been to compare the child's height with the height of both parents. Conventionally, according to Tanner et al (9), this has been expressed as the midparental height (TH) with a range of +/- 2.0 SD. In theory, however, the cTH $(10,28)$, with additional corrections for parent-parent and parentoffspring correlations, with a range of $+/-1.6$ would be expected to be superior. Our results suggest that the cTH range $(+/-1.6$ 
SD) may be too strict for defining FTS compared to the Tanner $\mathrm{TH}$ range (+/-2.0 SD). This is supported by a previous study showing that only $10 \%$ of healthy children show a HSDS outside their TH range (defined as +/-1.5 SD) (29) and by estimates that $50-90 \%$ of the height variation is accounted for by genetic factors (30).

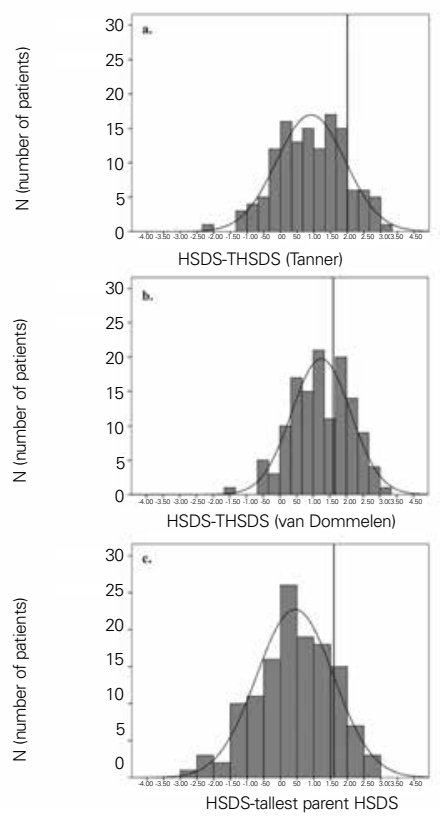

Figure 1. Distributions of HSDS distance to THSDS (a), conditional target height standard deviation score (b) and HSDS distance to tallest parental HSDS (c)

HSDS: height standard deviation score, THSDS: target height standard deviation score

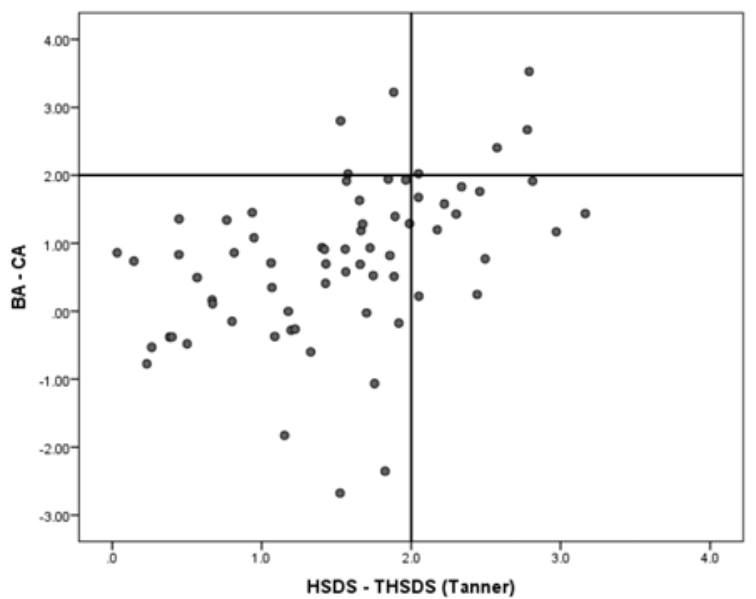

Figure 2. Correlation between HSDS distance to THSDS (according to Tanner) and bone age advancement HSDS: height standard deviation score, THSDS: target height standard deviation score, BA: bone age, CA: chronological age
An alternative approach is to compare the child's HSDS with the HSDS of the tallest parent. In theory, this would better accommodate genetic influences of dominant inheritance, inheritance of predominantly "tall" gene variants in case of discrepancy between parental heights $(1,20,29)$. However, no experimental data have been collected about the expected range around the difference between the child's HSDS minus the HSDS of the tallest parent. For the detection of pathological causes of tall stature, this approach appears as not suitable, because one of the most important disorders to diagnose (Marfan syndrome) is transmitted in a dominant fashion.

Most children with non-FTS show an advanced BA and can be labeled CAG. We have shown that their PAH is not different from that of children with FTS, confirming previous

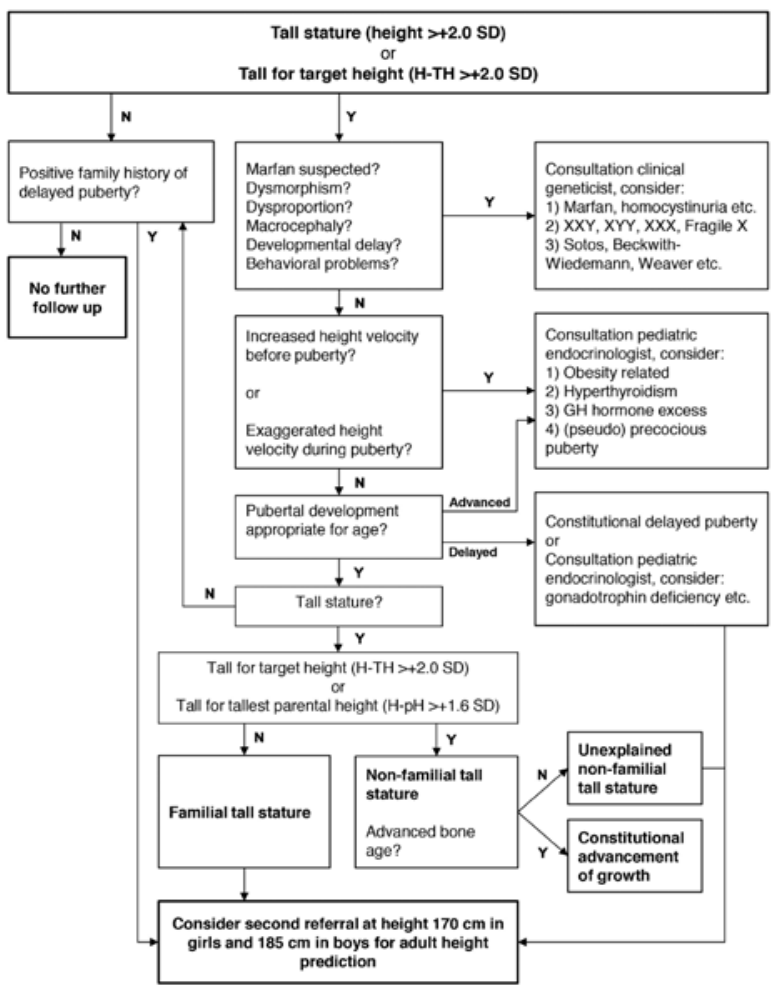

Figure 3. Proposed flow chart 0-17.99 years

Proposed flow chart for the diagnostic work-up of tall children aged 0-17.99 years. The flow chart consists of two main pathways. Initially, height standard deviation score and distance to target height (Tanner) are calculated. In case of a height standard deviation score $\leq 2.0$ or height standard deviation score -target height standard deviation score $\leq 2.0$, the child is classified as not-tall or not-tall for target height. We suggest that a second referral at height $170 \mathrm{~cm}$ before the age of 12.5 years in girls and $185 \mathrm{~cm}$ before the age of 14 years in boys for adult height prediction should be considered if a positive family history of delayed puberty is present. In case of a height standard deviation score $>2.0$ or height standard deviation score-target height standard deviation score $>2.0$, each subsequent step is aimed at excluding pathologic causes requiring further investigation and possibly treatment. The final step is to determine whether the tall child is familial tall or non-familial tall 
observations $(1,31)$. In our opinion, BA assessment remains an important tool in the differential diagnosis of tall stature.

Assessment of height velocity, expressed as a positive change of HSDS, is part of the diagnostic work-up, since increased height velocity may be associated with several rare hormonal causes of tall stature (secondary growth disorders such as precocious puberty, hyperthyroidism and $\mathrm{GH}$ excess) (1). We believe that the criterion of a change in HSDS >1.0, over an undefined period of time, may be a too strict rule in children over the age of 10 years (32), since an acceleration in height velocity is a normal phenomenon related to the pubertal stage. Therefore, we propose to first interpret the height velocity (1) in relation to pubertal development prior to performing additional work-up to exclude hormonal pathology. In case of doubt, a follow-up visit in three months' time to reconfirm normal pubertal growth and development may prevent unnecessary additional tests and costs. Pubertal development should be interpreted in relation to CA. Both precocious puberty and delayed puberty may be the result of underlying pathology. Precocious puberty causes increased height velocity and thus tall stature during childhood but a reduced adult height. In contrast, children with a delayed puberty may present with a normal stature during childhood but may reach a tall adult height (3).

A major reason for referral is to predict adult height and eventually consider adult height reduction. The present attitude of many pediatric endocrinologists is that interventions to reduce adult height are to be discouraged. Treating tall girls with estrogen preparations is considered obsolete by many, because of its association with fertility disorders in adulthood $(33,34)$. Treatment of tall boys with high-dose androgens is rather frequently associated with side effects, and its effect on adult height is limited (35). At present, only epiphysiodesis can be offered, which is associated with few complications in experienced hands (6). Our analysis showed that there is a large difference in numbers of patients with an indication for epiphysiodesis depending on which prediction method is used. Indeed, we demonstrated an overestimation of adult height according to Bayley and Pinneau (16), particularly in boys, compared to De Waal et al (17), as has been shown in previous studies. Therefore, we advise to use the method of De Waal et al (17) to calculate PAH, to avoid unnecessary referrals. If a BA is determined before girls have reached a height of $170 \mathrm{~cm}$ and boys $185 \mathrm{~cm}$, there is sufficient time to discuss the pros and cons of the intervention $(5,6)$.

It is noteworthy that out of the four children in whom epiphysiodesis was performed, one patient had a HSDS $\leq 2.0$ at first presentation. We therefore suggest that even in children who are not tall at first presentation, a second referral at height $170 \mathrm{~cm}$ before the age of 12.5 years in girls and $185 \mathrm{~cm}$ before the age of 14 years in boys for adult height prediction should be considered if a positive family history of delayed puberty is present.

Based on our results and review of the literature, we propose a new diagnostic flow chart (Figure 3). This flow chart uses a simple step by step strategy and suggests recommendations for follow-up. Initially, HSDS and distance to $\mathrm{TH}$ are calculated. Each subsequent step is aimed at discovering clues for pathologic causes with severe consequences (e.g. Marfan syndrome) or pathological causes requiring further investigation and possibly treatment (e.g. precocious puberty, hyperthyroidism, and growth hormone excess). The final steps are aimed at classifying children without any established pathology and providing recommendations for follow-up. We suggest a follow-up visit for children with unexplained NFTS and others who may be at risk for attaining an extreme tall stature at a time when they are expected to reach a height of 170 and 185 for girls and boys, respectively.

We acknowledge there are several limitations of this study. First, it is a retrospective study performed in a single centre in a general hospital; it is possible that our study population differs from that in other clinics, particularly academic clinics. Second, our study population contains a limited number of patients, and only few pathologic causes of tall stature were found, so only descriptive statistics could be performed. Third, it cannot be excluded that diagnoses may have been missed in the diagnostic work-up.

In conclusion, we found a low incidence of pathology in children referred for tall stature to a general paediatric clinic, and adult height reduction was seldom indicated. We suggest that the diagnostic work-up and follow-up can be minimal in most children, and propose a diagnostic algorithm for clinical practice.

\section{Acknowledgements}

We thank Dr. Wilma Oostdijk and Dr. Sabine Hannema for helpful comments on a previous version of the manuscript. We wish to thank Bea Jansen van't Land, Desirée Paap, Irene Bergsma, Lidi Schilperoort and Ingrid van de Woude for the good care for the patients at the growth clinic and for performing accurate auxological measurements.

\section{Authorship Contributions}

Ethics Committee Approval: Approval for the study was obtained by the Scientific Review Committee of Tergooi Hospitals (letter reference kv/15.05), Informed Consent: Not applicable, Concept: Frans B. Plötz, Gerdine A. Kamp, Design: Frans B. Plötz, Gerdine Kamp, Jan M. Wit, Anke Pons, Susanne E. Stalman, Data Collection or Processing: Anke Pons, Susanne E. Stalman, Analysis or Interpretation: Anke Pons, Susanne E. Stalman, Jan M. Wit, Frans B. Plötz, Gerdine A. Kamp, Literature Search: Anke Pons, Jan M. Wit, Susanne E. Stalman, Writing: Anke Pons, Susanne E. Stalman, Jan M. Wit, Frans B. Plötz, Gerdine A. Kamp, Peer-review: Internal peer-reviewed, Financial Disclosure: Funding was provided by Tergooi Hospitals, Blaricum, The Netherlands. The sponsor has no involvement in the study. 


\section{References}

1. Davies $\mathrm{JH}$, Cheetham T. Investigation and management of tall stature. Arch Dis Child 2014;99:772-777. Epub 2014 May 15

2. Drop SL, De Waal WJ, de Muinck Keizer-Schrama SM. Sex steroid treatment of constitutionally tall stature. Endocr Rev 1998; 19:540-558.

3. Wit JM, Ranke MB, Kelnar CJH. ESPE Classification of Pediatric Endocrine Diagnoses. Horm Res Paediatr 2007;68:1120.

4. Visser R, Kant SG, Wit JM, Breuning MH. Overgrowth syndromes. from classical to new. Pediatr Endocrinol Rev 2009;6:375-394.

5. Odink RJ, Gerver WJ, Heeg M, Rouwe CW, van Waarde WM, Sauer PJ. Reduction of excessive height in boys by bilateral percutaneous epiphysiodesis around the knee. Eur $\mathrm{J}$ Pediatr 2006;165:50-54. Epub 2005 Oct 26

6. Benyi E, Berner M, Bjernekull I, Boman A, Chrysis D, Nilsson $\mathrm{O}$, Waehre A, Wehtje H, Savendahl L. Efficacy and safety of percutaneous epiphysiodesis operation around the knee to reduce adult height in extremely tall adolescent girls and boys. Int J Pediatr Endocrinol 2010;2010:740629. Epub 2010 Dec 2

7. Hochberg Z. Practical algorithms in pediatric endocrinology. Basel, Karger, 2007.

8. Greulich WW, Pyle SI. Radiograph atlas of skeletal development of the hand and wrist. Stanford, Stanford University Press, 1959.

9. Tanner JM, Goldstein $H$, Whitehouse $R H$. Standards for children's height at ages 2-9 years allowing for heights of parents. Arch Dis Child 1970;45:755-762.

10. van Dommelen $P$, Schönbeck $Y$, van Buuren S. A simple calculation of the target height. Arch Dis Child 2012;97:182. Epub 2011 Dec 18

11. Schönbeck $Y$, Talma $H$, van Dommelen P, Bakker B, Buitendijk SE, HiraSing RA, van Buuren S. The world's tallest nation has stopped growing taller: the height of Dutch children from 1955 to 2009. Pediatr Res 2013;73:371-377. Epub 2012 Dec 10

12. Cole TJ, Roede MJ. Centiles of body mass index for Dutch children aged 0-20 years in 1980-a baseline to assess recent trends in obesity. Ann Hum Biol 1999;26:303-308.

13. Fredriks AM, van Buuren $S$, Burgmeijer RJ, Meulmeester JF, Beuker RJ, Brugman E, Roede MJ, Verloove-Vanhorick SP, Wit JM. Continuing positive secular growth change in The Netherlands 1955-1997. Pediatr Res 2000;47:316-323.

14. Fredriks AM, van Buuren $S$, van Heel WJ, Dijkman-Neerincx $\mathrm{RH}$, Verloove-Vanhorick SP, Wit JM. Nationwide age references for sitting height, leg length, and sitting height/ height ratio, and their diagnostic value for disproportionate growth disorders. Arch Dis Child 2005;90:807-812. Epub 2005 Apr 29

15. Niklasson A, Ericson A, Fryer JG, Karlberg J, Lawrence C, Karlberg P. An update of the Swedish reference standards for weight, length and head circumference at birth for given gestational age (1977-1981). Acta Paediatr Scand 1991;80:756-762.

16. Bayley N, Pinneau SR. Tables for predicting adult height from skeletal age: revised for use with the Greulich-Pyle hand standards. J Pediatr 1952;40:423-441.

17. De Waal WJ, Stijnen T, Lucas IS, van Gurp E, de Muinck KeizerSchrama S, Drop SL. A new model to predict final height in constitutionally tall children. Acta Paediatr 1996;85:889-893.
18. Marshall WA, Tanner JM. Variations in pattern of pubertal changes in girls. Arch Dis Child 1969;44:291-303.

19. Marshall WA, Tanner JM. Variations in the pattern of pubertal changes in boys. Arch Dis Child 1970;45:13-23.

20. Liu F, Hendriks AE, Ralf A, Boot AM, Benyi E, Savendahl L, Oostra BA, van Duijn C, Hofman A, Rivadeneira F, Uitterlinden AG, Drop SL, Kayser M. Common DNA variants predict tall stature in Europeans. Hum Genet 2014;133:587-97. Epub 2013 Nov 20

21. de Boer $L$, Kant SG, Karperien $M$, van Beers $L$, Tjon J, Vink GR, van Tol D, Dauwerse H, le Cessie S, Beemer FA, van der Burgt I, Hamel BC, Hennekam RC, Kuhnle U, Mathijssen IB, Veenstra-Knol HE, Stumpel CT, Breuning MH, Wit JM. Genotype-phenotype correlation in patients suspected of having Sotos syndrome. Horm Res 2004;62:197-207. Epub 2004 Sep 24

22. van Buuren S. Puberty Plot Pro Web Application. Available at: http://vps.stefvanbuuren.nl/puberty/

23. Simm PJ, Werther GA. Child and adolescent growth disorders-an overview. Aust Fam Physician 2005;34:731737.

24. Morris JK, Alberman E, Scott C, Jacobs P. Is the prevalence of Klinefelter syndrome increasing? Eur J Hum Genet 2008;16:163-170. Epub 2007 Nov 14

25. Ramirez F, Dietz HC. Marfan syndrome: from molecular pathogenesis to clinical treatment. Curr Opin Genet Dev 2007; 17:252-258. Epub 2007 Apr 27

26. Tatton-Brown K, Rahman N. Sotos syndrome. Eur J Hum Genet 2007;15:264-271. Epub 2006 Sep 13

27. Thorburn MJ, Wright ES, Miller CG, Smith-Read EH. Exomphalos-macroglossia-gigantism syndrome in Jamaican infants. Am J Dis Child 1970;119:316-321.

28. Hermanussen M, Cole J. The calculation of target height reconsidered. Horm Res 2003;59:180-183.

29. Wright CM, Cheetham TD. The strengths and limitations of parental heights as a predictor of attained height. Arch Dis Child 1999;81:257-260.

30. Verge CF, Mowat D. Overgrowth. Arch Dis Child 2010;95:458463. Epub 2010 Apr 6

31. Papadimitriou A, Kanakis G, Douros K, Papadimitriou DT, Boutsiadis AH, Nicolaidou $P$, Fretzayas A. Constitutional advancement of growth is associated with early puberty in girls. Horm Res Paediatr 2011;76:273-277. Epub 2011 Aug 22

32. Drop SL, Greggio N, Cappa M, Bernasconi S; International Workshop on Management of Puberty for Optimum Auxological Results. Current concepts in tall stature and overgrowth syndromes. J Pediatr Endocrinol Metab 2001;14(Suppl 2):975-984.

33. Hendriks AE, Drop SL, Laven JS, Boot AM. Fertility of tall girls treated with high-dose estrogen, a dose-response relationship. J Clin Endocrinol Metab 2012;97:3107-3114. Epub 2012 Jun 20

34. Venn A, Bruinsma F, Werther G, Pyett $P$, Baird $D$, Jones $P$, Rayner J, Lumley J. Oestrogen treatment to reduce the adult height of tall girls: long-term effects on fertility. Lancet 2004;364:1513-1518.

35. Hendriks AE, Boellaard WP, van Casteren NJ, Romijn JC, de Jong FH, Boot AM, Drop SL. Fatherhood in tall men treated with high-dose sex steroids during adolescence. J Clin Endocrinol Metab 2010;95:5233-5240. Epub 2010 Sep 8 